$\begin{array}{ll}\text { Abstracta Iranica } & \begin{array}{l}\text { Abstracta Iranica } \\ \text { Revue bibliographique pour le domaine irano-aryen }\end{array} \\ & \text { Volume } \mathbf{2 9 |} \mathbf{2 0 0 8} \\ & \text { Comptes rendus des publications de } \mathbf{2 0 0 6}\end{array}$

\title{
La religion discrète. Croyances et pratiques spirituelles dans l'islam shi'ite. Paris, Vrin, 2006, 416 p.
}

Denis Hermann

\section{OpenEdition}

1 Journals

\section{Édition électronique}

URL : http://journals.openedition.org/abstractairanica/30212

DOI : 10.4000/abstractairanica.30212

ISSN : 1961-960X

Éditeur :

CNRS (UMR 7528 Mondes iraniens et indiens), Éditions de l'IFRI

\section{Édition imprimée}

Date de publication : 15 mai 2008

ISSN : 0240-8910

\section{Référence électronique}

Denis Hermann, «La religion discrète. Croyances et pratiques spirituelles dans l'islam shi'ite. Paris, Vrin, 2006, 416 p. », Abstracta Iranica [En ligne], Volume 29 | 2008, document 283, mis en ligne le 15 septembre 2008, consulté le 26 septembre 2020. URL : http://journals.openedition.org/ abstractairanica/30212 ; DOI : https://doi.org/10.4000/abstractairanica.30212

Ce document a été généré automatiquement le 26 septembre 2020.

Tous droits réservés 


\title{
La religion discrète. Croyances et pratiques spirituelles dans l'islam shi'ite. Paris, Vrin, 2006, 416 p.
}

\author{
Denis Hermann
}

1 Pendant très longtemps il existait peu d'études sur le shi'isme, qu'il s'agisse de ses aspects théologiques et spirituels ou historiques et idéologiques. Les études ont en fait débuté après la révolution islamique iranienne (1978-80) qui a aussi marqué le regain de politisation des populations shi'ites d'Irak et du Liban. La chute du régime de Saddam Hossein en 2003 et l'émergence d'un premier état shi'ite arabe a encore accéléré ce processus. Mohammad Ali Amir-Moezzi, l'un des spécialistes et connaisseurs des textes originaux du shi' isme duodécimain et en particulier du hadīt, a réédité dans ce volume quatorze de ses principaux articles, publiés entre 1992 et 2005. Dix d'entre eux correspondent à la série complète des Aspects de l'imamologie duodécimaine (AID) qui traite de la seule figure de l'imâm dans le shi'isme duodécimain. Cette dernière question peu étudiée jusqu'à présent hormis par Henry Corbin domine donc l'ensemble de l'ouvrage. Cette édition forme un tout cohérent divisée en quatre thèmes différents qui marquent l'évolution de la pensée shi'ite. Le titre à première vue surprenant, La religion discrète, est justifié par l'A. dans sa préface pour une raison fondamentale : le shi'isme apparaît dans ses textes fondateurs et dans l'œuvre d'une grande partie de ses savants comme une doctrine initiatique et ésotérique. L'A. considère que deux pratiques importantes propres à cette religion vont dans ce sens, la garde du secret (taqiyya) et la dispersion des informations (tabdid al-'ilm). Celles-ci font du shi' isme une religion par essence "discrète".

2 Table des matières : Première section : Premières émergences et convergences anciennes : «Considérations sur l'expression dìn 'Alī. Aux origines de la foi shi ite », pp. 19-47; « Shahrbânû, Dame du pays d'Iran et Mère des imams : entre l'Iran préislamique et le shi'isme imamite ", pp. 49-86. Deuxième section : De la nature de l'Imam. Initiation et dualisme : « Remarques sur la divinité de l'Imam », pp. 89-108; « La préexistence de l'Imam », pp. 109-133; « L'Imam dans le ciel. Ascension et initiation », pp. 
135-150 ; «Savoir c'est pouvoir. Exégèses et implications du miracle dans l'imamisme ancien ", pp. 151-175; " Notes à propos de la walāya imamite ", pp. 177-207 ; "Seul l'homme de Dieu est humain. Théologie et anthropologie mystique à travers l'exégèse imamite ancienne ", pp. 209-228. Troisième section : Pratiques herméneutiques et pratiques spirituelles : " Le Combattant du ta'wìl. Un poème de Mollā Ṣadrā sur 'Alī », pp. 231-251; «Visions d'Imams en mystique duodécimaine moderne et contemporaine ", pp. 253-276; « Notes sur la prière dans le shi'isme imamite », pp. 277-294. Quatrième section : Aspects de l'eschatologie individuelle et collective : " Fin du Temps et Retour à l'Origine ", pp. 297-315; "Contribution à la typologie des rencontres avec l'imam caché », pp. 317-336 ; «Une absence remplie de présence. Herméneutiques de l'Occultation chez les Shaykhiyya », pp. 337-355.

Pour un c.r. plus détaillé voir le site de l'IISMM :

4 http://iismm.ehess.fr/document.php?id=223.

\section{INDEX}

Thèmes : 7. Islam

\section{AUTEURS}

DENIS HERMANN

Paris 